Eos, Vol. 77, No. 38, September 17, 1996

EOS, TRANSACTIONS, AMERICAN GEOPHYSICAL U I O N

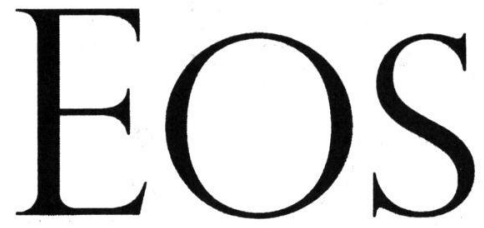

VOLUME 77 NUMBER 38

SEPTEMBER 17, 1996

PAGES 365-376

\title{
Study Yields Surprises About Seafloor Spreading in back-arc Basins
}

PAGES 365, 368-369

Etienne Ruellan, Yves Lagabrielle, Manabu Tanahashi, and the Shipboard Party

A study of the seafloor in the North Fiji Basin is leading to a better understanding of the geometry and evolution of spreading in backarc basins. Two of the most important features of the area, the South Pandora Ridge and the Tripartite Ridge, belong to a presently active spreading system that began forming at least 7.2 m.y.a. The ridges spread at an average rate of about $1.6 \mathrm{~cm} / \mathrm{yr}$. By studying the segments of the ridges in greater detail, researchers found that each was either a "tectonic type," with a more or less complex deep axial valley, or a "volcanic type," with a high, rifted volcanic massif occupying the axial domain.

For more information, contact Etienne Ruellan, CNRS, Géosciences Azur, 250 Rue A. Einstein, Sophia Antipolis, 06560 Valbonne, France; ruellan@faille.unice.fr.
These observations demonstrate that even in back-arc environments, and along spreading centers with low spreading rates, the geophysical signature, as well as the morphotectonic and volcanic characteristics of the axial domain, are similar to those found along low-rate spreading axes of wide oceans. Therefore the physical parameters characteristic of deep mantle processes responsible for oceanic expansion are similar in both evolved back-arc basins and large, old oceans. Second, the data show that two orthogonal spreading systems may be active simultaneously in a back-arc basin environment even when there is no expected topographic feature of a typical tectonic and magmatic connection such as a triple junction or transform fault.

Studying the geometric patterns of the seafloor at mid-oceanic ridges is one of the best ways of measuring the stability of spreading processes over space or time. Recent surveys of mid-oceanic ridges in the oceans and in back-arc basins reveal that geometries of the active axis are highly variable, closely reflecting the instability of the spreading processes. These geometric changes are seen in nonlinear patterns of the active spreading center, frequent changes of trend of the axis, poorly organized relay zones, and rapid variability of the morphological characteristics across and along strike; for example, segments with sharp and deep axial depressions can change suddenly into segments showing flat or domelike sections, with little or no axial valley.

Furthermore, frequent changes in the location and the nature of the structures forming the spreading axis reflect rapidly changing stress regimes in the lithosphere. By studying environments with unstable geometry along their spreading axes, a better understanding can be obtained of the interactions between changes in stresses at the surface and the dynamics of the upper mantle below the spreading axis.

The cruise was held in August and September 1994 in the North Fiji Basin (NFB), one of the best examples of a back-arc basin environment. Variability in the geometry of active spreading systems at the NFB is well documented. The cruise, on board the French R/V L'Atalante, was the first operation of the FrenchJapanese New-Starmer cooperation program

Fig. 1. Swath mapping bathymetry (in meters) from North Fiji cruise and Starmer data. The South Pandora Ridge and the Tripartite Ridge spreading axes (mainly in red, yellow and purple) make up a roughly east-west broad arch. The axes are divided in several segments by trans
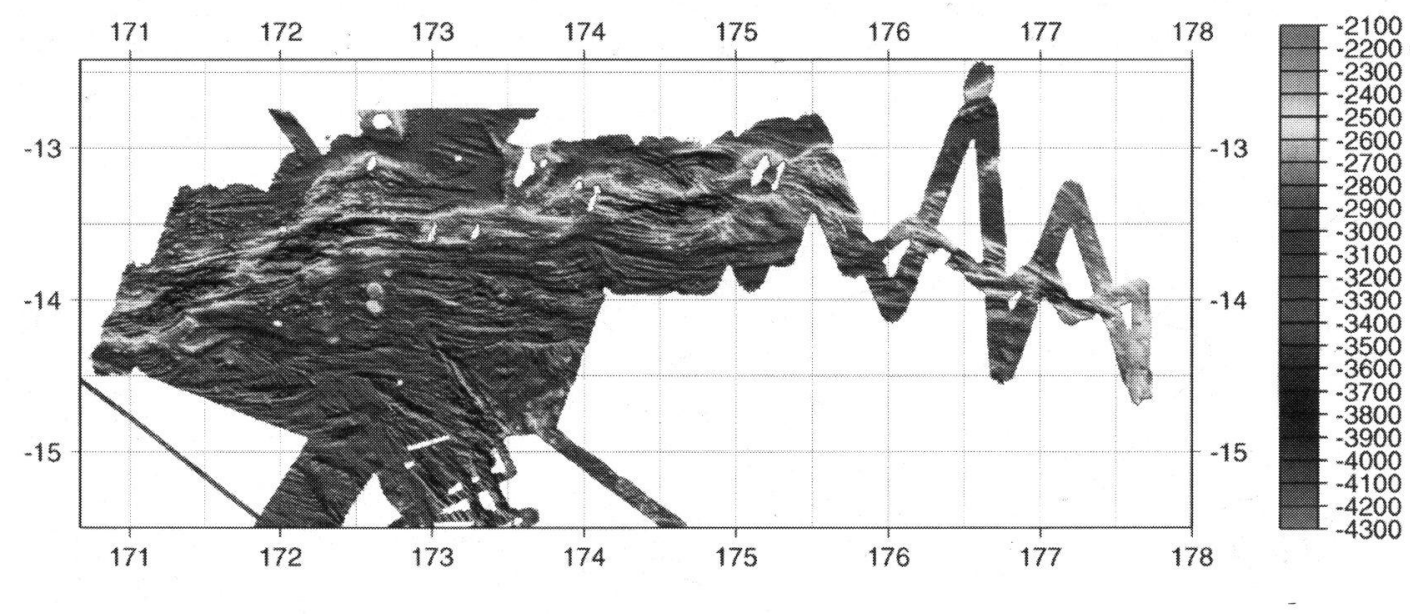

form zones. Out-

side, the seafloor of the Central Plateau displays a tectonic pattern linked to this spreading. In the southern area, the Central Spreading Ridge of the North Fiji Basin (mainly northwest-southeast) ends against the Central Plateau. Original color image appears at the back of this volume. 


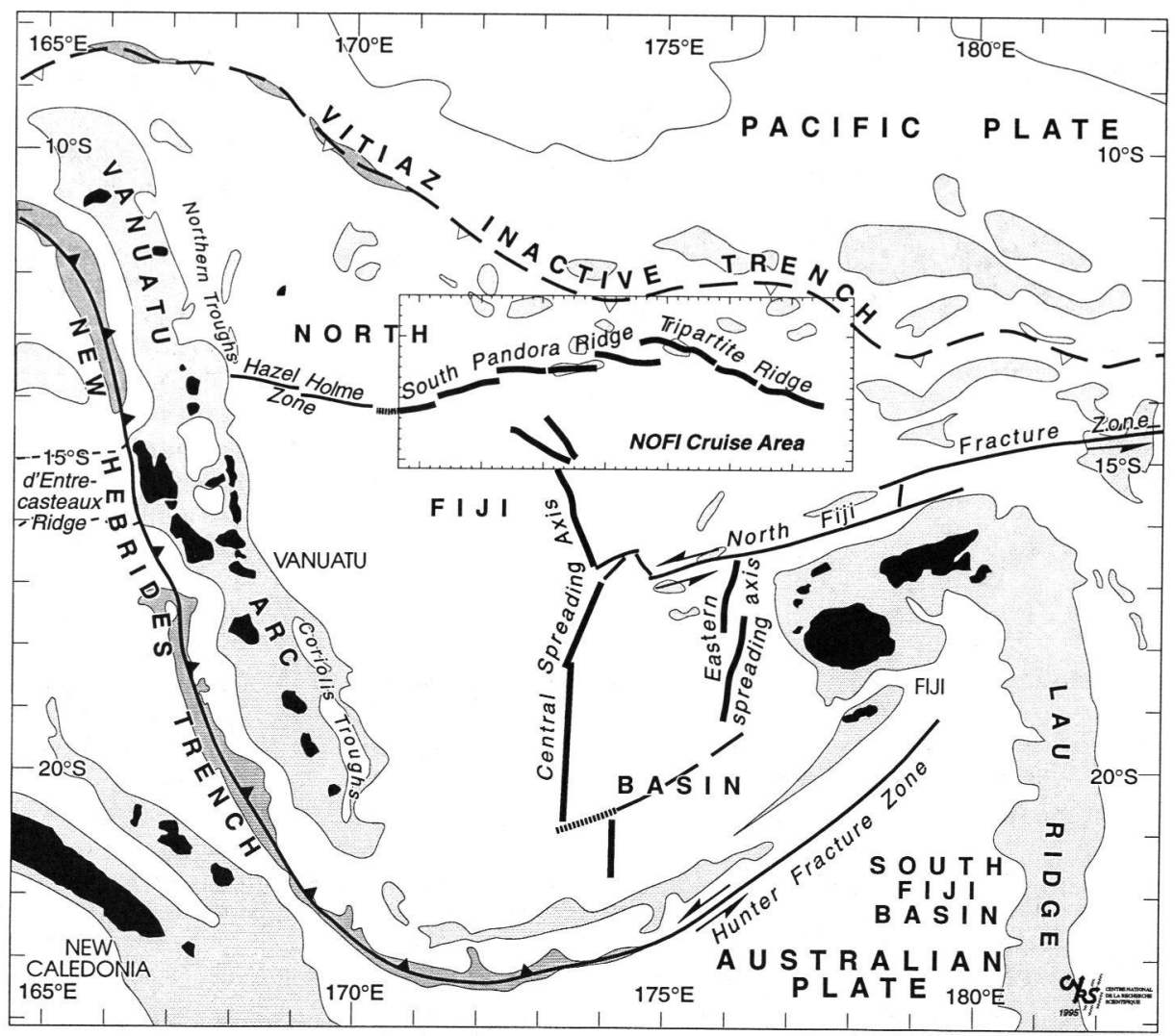

Fig. 2. Geodynamic setting of the North Fiji Basin (NFB) in the southwestern Pacific. The cruise investigated the boxed area in the center.

on the study of active spreading systems in back-arc basins of the South West Pacific.

\section{Cruise Fails to Uncover a Junction}

Surveys conducted during the last 12 years reveal a complex geometry of the area's spreading centers [Auzende et al., 1990]. The active system is composed of several features [Pelletier et al., 1993]. The main north-south trending central ridge (the Central Spreading Ridge, CSR) is $800 \mathrm{~km}$ long and consists of segments with various orientations and morphologies [Lafoy et al., 1990; de Alteriis et al., 1993; Ruellan et al., 1994]. A subordinate, east spreading system (the West Fiji Ridge, WFR, or Wiva Rift) has a twin, arcuate axis. Both active systems are connected through the North Fiji Fracture Zone [Kroenke et al., 1991]. The main target of the cruise was where this complex active system was believed to connect to the east-west trending South Pandora Ridge (SPR)-Tripartite Ridge (TR) system (Figure 1). The geometry, structure, and kinematics of this junction remained unknown up to the cruise.

The tectonic configuration of the North Fiji Basin has been in question since Chase [1971] proposed plate boundary geometries and a kinematic reconstruction of the basin opening. Many models have been proposed, especially for the northern part of the basin, but they all lack constraints. Therefore another focus of the North Fiji cruise was to collect data for updating the tectonic map of the northern NFB. These data will be added to the results of previous surveys conducted in the North Lau region to better constrain models of tectonic evolution and plate boundary kinematics along the northern boundary of the Fiji platform.

\section{Valuable Data Collected}

During the cruise, swath mapping, geophysics research, and rock sampling was conducted between $13^{\circ} \mathrm{S}$ and $15^{\circ} \mathrm{S}$ and $171^{\circ} \mathrm{E}$ and $178^{\circ} \mathrm{E}$ (Figure 2). The active spreading centers of both the South Pandora and Tripartite ridges were surveyed continuously along the axis. Both bathymetry (Figure 1) and imagery (Figure 3 ) were obtained within a $200 \times 500-\mathrm{km}$ area, providing full-coverage swath mapping. Air gun seismic profiling was performed along most of the survey track lines, which run northeast and are spaced at 8-mile intervals. The magnetic field was almost continuously recorded using a standard towed proton-precession magnetometer and a recently developed three-component magnetometer. Gravity data were acquired continuously. Dredging and piston coring were also performed at nine sites.

\section{General Tectonic Pattern}

The South Pandora Ridge and the Tripartite Ridge axial domains make up a broad arch that runs roughly east-west (Figure 1). The axis is tectonically and volcanically active, as documented by its high reflectivity (see yellow and green in Figure 3); this reflectivity is the result of the lack of sedimentary cover, the occurrence of recent volcanic eruptions, and tectonic disruptions.

The mean trend of the axial area changes from $\mathrm{N} 65^{\circ} \mathrm{E}$ in the western part to $\mathrm{N} 90^{\circ} \mathrm{E}$ in the center to $\mathrm{N} 110^{\circ} \mathrm{E}$ in the eastern part. The changes in the direction of the ridge occur at several discontinuities with various geometrical patterns, which suggests complex transform relay zones such as spreading offsets or large-scale overlapping centers. The active domain is about $20 \mathrm{~km}$ wide and corresponds either to bathymetric highs or to deep elongated grabens located on top of the regional dome that forms the SPR and TR. The bathymetric highs represent volcanic building, which sometimes obstruct the axial valley. The grabens show the typical morphology of a slow spreading axis, with two steep walls flanking a 10-20 km wide and 3000-4800-m-deep axial valley. Elongated neovolcanic ridges are present within the axial valleys, and lateral volcanic ridges are located on both sides of the graben.

Many volcanoes ranging from one to several kilometers in diameter (Figure 4) are found along the northern domain (about $3000 \mathrm{~m}$ deep) bordering the SPR. A thin sedimentary cover lies over the plateau. On the southern edge of the SPR-TR lies a broad central plateau (about $2700 \mathrm{~m}$ deep) also covered by a thin sedimentary cover. In the eastern part, the tectonic pattern is mainly east-west, parallel to the SPR, and volcanic seamounts dot the western part. The eastwest structures suggest that the domain was formed at the SPR and that the active spreading center migrated northwestward, relatively. The entire area is characterized by large-scale deformations.

\section{The South Pandora-Tripartite Spreading Ridge}

The axial domain can be divided into two first-order segments: the SPR and the TR (Figure 4). These two segments differ mainly in their respective orientations, $\mathrm{N} 80^{\circ} \mathrm{E}$ for the SPR and $\mathrm{N} 110^{\circ} \mathrm{E}$ for the TR, and they are separated by a wide overlapping spreading structure. The South Pandora Ridge is $470 \mathrm{~km}$ long with a general trend of $\mathrm{N}^{\circ} 0^{\circ} \mathrm{E}$. The sedimentary cover is absent or very thin over a distance of $100 \mathrm{~km}$ from both sides of the active axis, which suggests that spreading has occurred along the SPR for a few million years.

The South Pandora Ridge is divided into five second-order sections (SPR0 to SPR4) 


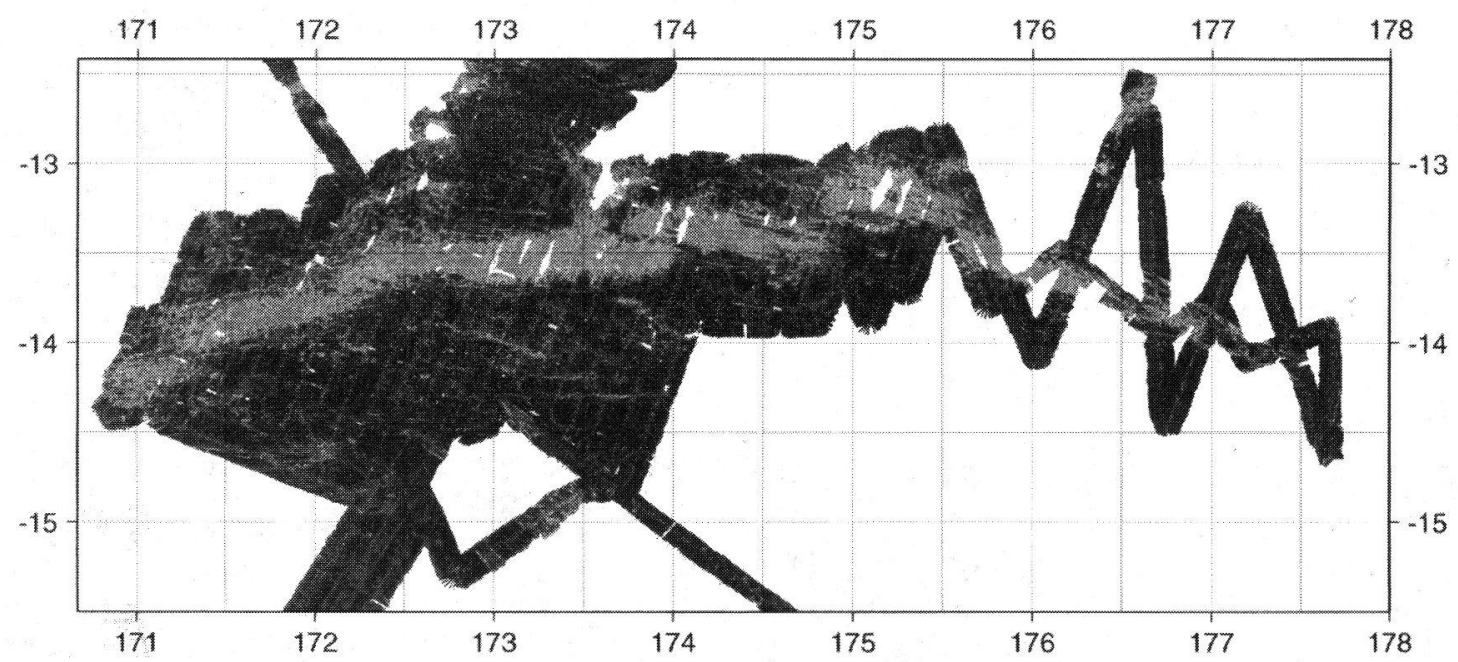

Fig. 3. Swath mapping imagery from North Fiji cruise and Starmer data. The high reflectivity (see yellow and green) indicates the tectonically and volcanically active area, especially the South Pandora-Tripartite Ridge, and also the northern end of the Central Spreading Ridge (lower intensity). The two active spreading systems are separated by a wide low reflectivity area (the Central plateau) without remarkable active tectonic or magmatic features such as a triple junction or a transform fault. Original color image appears at the back of this volume. that are 120-60 km long. SPR0, a 100-km-long trending segment, consists of a 4100-m deep graben flanked by two volcanic highs with a neovolcanic ridge inside. Segment SPR1 has an elongated east-west-trending axial volcanic high that is rifted by two sets of faults. Segment SPR2 shows a bathymetric transverse section similar to those of slow-spreading ridges; it consists of an east-west-trending valley flanked by two lateral ridges. Segment SPR3 marks a clear change in the global trend of the SPR; it consists of a central volthird-order segments characterized by axial valleys. The eastern section, named "NOFI deep," is the deepest point ( $-4787 \mathrm{~m})$ of the NFB in which deep crustal rocks were dredged during the North Fiji survey. Segment SPR4 is at least $60 \mathrm{~km}$ long, but it may extend farther west. It axial valley bounded by noncontinuous lateral ridges. The junctions between the segments do not appear as typical transform faults. The segments are separated by 10 30-km-wide offsets oblique structures and lower reflectivity patterns (Figure 3 ), indicating that complex transform zones lie between the canic high that changes along strike to two shows a complex with complex segments. In these zones, diffused transfer of extensional tectonic motion occurs.

The Tripartite Ridge is $350 \mathrm{~km}$ long and trends east-southeast. It consists of three segments (TR1 to TR3). Devoid of sedimentary cover, the Tripartite Ridge appears to be a young feature that is propagating into an older oceanic lithosphere. Segment TR1 is $120 \mathrm{~km}$ long; its axis consists of two grabens separated by a median volcanic high. Segment TR2 is $70 \mathrm{~km}$ long and comprises the Çakabau Seamount and an associated eastwest graben on its eastern edge. Segment TR3 is $150 \mathrm{~km}$ long and curved; it is composed of two elongated axial grabens separated by a median volcanic high that lie near the junction between the TR and the Rotuma Ridge.
The SPR-TR junction corresponds to a major discontinuity of the spreading system. The general tectonic geometry displays clear similarities with largescale overlapping spreading centers (OSC) observed on ocean spreading ridges. It is composed of the westernmost graben of the TR and a graben that belongs to the eastern tip of SPR. The offset between the two arms is $25 \mathrm{~km}$ wide and the overlap is $40 \mathrm{~km}$-long. The seafloor beexhibits oblique intersected fabrics. This pattern strongly suggests that this area is the transform zone.

\section{Unusual Geology Between Ridges}

The relationships between the South Pandora Ridge-Tripartite Ridge and the Central Spreading Ridge are uncommon. The two spreading systems are separated by the broad Central Plateau (Figure 4). The northern termination of the CSR is marked by a set of northeast-trending horsts and grabens set in fan that are limited by faults. On the other hand, this part of the CSR displays a rather low reflectivity (Figure 3 ), which suggests decreased magmatic activity. The structure ends to the north against the Central Plateau, tween the ridges

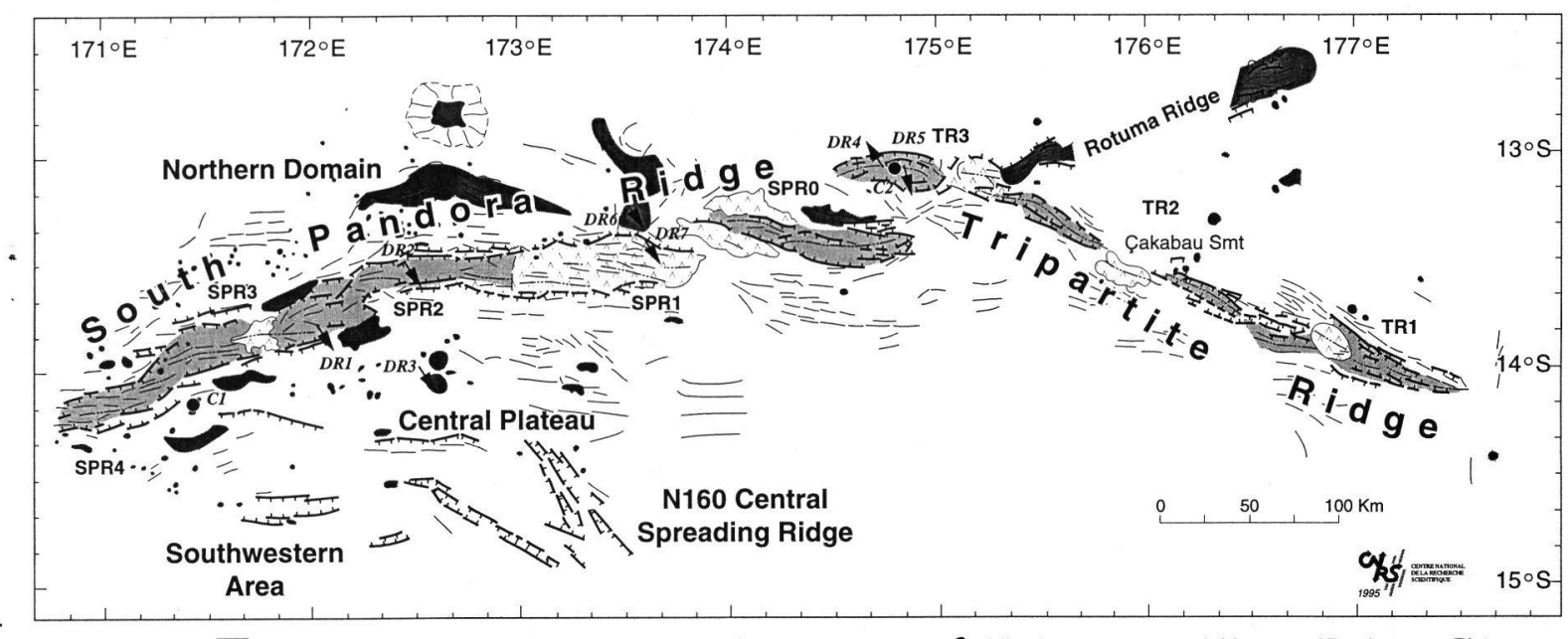

Axial Valley $\square$ Axial volcanic high $>$ Main fault scarps - Scarps - Axis $\bullet$ Off axis seamounts and ridges Dredges - Piston core

Fig. 4. Simplified structural map of the South Pandora Ridge and the Tripartite Ridge based on data gathered during the NorhthFiji cruise. The major structural domains were deduced from swath mapping bathymetry and imagery and from seismic lines. SPRO to SPR4 are the second-order segments of the South Pandora Ridge; TR1 to TR3 are the second-order segments of the Tripartite Ridge. 
where east-west trending structures suggest that the structure was formed at the axis of the SPR.

Westward, on the other hand, the device in fan finishes in the southwestern area, which has peculiar overlapped struclures (Figure 2). The most remarkable of these, oriented roughly east-west, are clearly curved to the north at their eastern ends. These structures are closely associated with a second set of faults trending northwest-southeast. Thus there is no typical transform tectonic feature such as triple junction or transform fault between the two ridges: the bathymetry does not show evidence of transform structure between the two axes, and no active magmatic area appears on the swath mapping imagery. Does this suggest that the SPR-TR and the CSR are two disconnected spreading systems inside the North Fiji Basin?

\section{Magnetics}

The first analysis of data from the cruise shows that scalar magnetic anomalies can be correlated among profiles crossing the South Pandora Ridge, the Tripartite Ridge, and the Rotuma Ridge. The anomalies define lineations and interruptions that closely follow the tectonic pattern as well as the offsets of the spreading axis.

Researchers identified anomalies on both flanks of the SPR that suggest the SPR is at least $7.2 \mathrm{~m} . y$. old. Spacing of the anomalies does not vary significantly along the SPR, which is consistent with a fairly constant spreading rate of about $1.6 \mathrm{~cm} / \mathrm{yr}$. Neverthe- less, spreading rates can vary locally as a result of oblique and asymmetric spreading. Despite a poorer data coverage, the magnetic lineations associated with the TR seem to get closer to the east on both flanks, suggesting that spreading rates decreased eastward.

\section{Gravity}

As expected, the distribution of free-air anomalies corresponds to the topographic features of the South Pandora and Tripartite ridges, as revealed by the bathymetric and sonar imagery surveys. Along the SPR, each segment produces a free-air anomaly signature. A first three-dimensional map of mantle Bouguer anomalies of the SPR agree with the tectonic segmentation of the ridge. Very low mantle Bouguer anomalies over the eastern segment reflect high magma supply and a thick crust, while relatively higher values over the North Fiji deep confirm the presence of a thinner crust. Over the Tripartite Ridge, the Cakabau Seamount (TR2 segment) produces a large positive anomaly.

\section{Acknowledgments}

The scientific team embarked for the North Fiji cruise thanks to the officers and the crew of the R/V L'Atalante and the technical team of GENAVIR. Data used in the figures were processed using Trismus and Imagem softwares (IFREMER), GMT software [Wessel and Smith, 1991], and IFO softwares (CNRSINRIA). Contribution number 57 of Géosciences Azur.

\section{Shipboard Party}

Etienne Ruellan, Yves Lagabrielle, Manabu Tanahashi, Jacques Bourgois, Georges Buffet, Giovanni de Alteriis, Jérôme Dyment, Jean Goslin, Eulalia Gracia, Yo Iwabuchi, Philip Jarvis, Masato Joshima, Anne-Marie Karpoff, Takeshi Matsumoto, Hélène Ondreas, Bernard Pelletier, and Olivier Sardou.

\section{References}

Auzende, J. M., E. Honza, et al., Active spreading and hydrothermalism in North Fiji basin (SW Pacific), Results of JapaneseFrench cruise Kaiyo 87, Mar. Geophys. Res., I2, 269, 1990.

de Alteriis, G., E. Ruellan, J. M. Auzende, H Ondréas, V. Bendel, E. Gràcia Mont, Y. Lagabrielle, P. Huchon, and M. Tanahashi, Propagating rifts in the North Fiji Basin (Southwest Pacific), Geology, 21, 583 1993.

Chase, C.G., Tectonic history of the Fiji Plateau, Geol. Soc. Am. Bull., 82, 3087-3110 1971 .

Kroenke, L., R. C. Price, and P. A Jarvis, North Fiji basin northern limb of the triple junction. Sidescan sonar imagery and bathymetry, in Pacific Seafloor Atlas, Hawai Institute of Geophysics, Honolulu, 14 pp., 1991.

Lafoy, Y., J. M. Auzende, E. Ruellan, P. Huchon, and E. Honza, The $16^{\circ} \mathrm{N} 40^{\circ} \mathrm{S}$ triple junction in the North Fiji basin ( $S W$ Pacific), Mar. Geophys. Res., 12, 285, 1990.

Pelletier, B., Y. Lafoy, and F. Missegue, Morphostructure and magnetic fabric of the northwestern North Fiji Basin, Geophys. Res. Lett., 20, 1151, 1993.

Ruellan, E., P. Huchon, J. M. Auzende, and E. Gràcia, Propagating rift and overlapping spreading center in the North Fiji Basin, Mar. Geol., I16, 37, 1994.

\section{Teachers, Administrators Look to a Higher Standard}

\section{PAGES $365-366$}

\section{The second article in a two-part series.}

With so much 20th century progress having been fueled by scientific achievements, some American leaders are genuinely concerned about running out of intellectual gas. Science has long driven the engines of industry, yet many American workers do not seem to understand the very processes of scientific inquiry and invention that put them to work in the first place.

In a survey of conducted by the Bayer Corporation and reported in April, more than $60 \%$ of corporate human resource directors and $40 \%$ of elementary school principals said that most young Americans lack adequate science preparation for entry-level jobs in industry. Close to $84 \%$ of the resource directors surveyed said that they expect science literacy to be a requirement for entry level jobs in the next century, yet $75 \%$ said that they may not have a proper workforce to meet those qualifications.

Similarly, the Science \& Engineering Indicators 1996 compiled by the National Science Board (Eos, August 27, 1996), reveals that just $9 \%$ of a diverse cross section of Americans said that they felt "very well informed" about science and technology. Only $23 \%$ understood the nature of scientific inquiry well enough to judge the scientific basis of the results of an experiment.

"Most people do not get a basic education in the sciences, and they're not getting enough subsequent education and exposure to science," says Shirley Malcolm, head of the Directorate of.Education and Human Resources Programs at the American Association for the Advancement of Science.

According to Malcolm and to Jon Miller, vice president of the Chicago Academy of Sci-
Table 1. Content Standards for Earth and Space Science

\begin{tabular}{ll}
\multicolumn{1}{c}{$\begin{array}{c}\text { Table 1. } \\
\text { Earth and Space Science }\end{array}$} \\
\hline Grade Level & \multicolumn{1}{c}{ Content Standard } \\
\hline $\mathrm{K}-4$ & $\begin{array}{l}\text { properties of Earth materials } \\
\text { objects in the sky } \\
\text { changes in Earth and sky } \\
\text { structure of the Earth system } \\
5-8\end{array}$ \\
$\begin{array}{l}\text { Earth's history } \\
\text { Earth in the solar system } \\
\text { energy in the Earth system } \\
\text { geochemical cycles } \\
\text { origin and evolution of the } \\
\text { Earth system } \\
\text { origin and evolution of the } \\
\text { universe }\end{array}$ \\
\end{tabular}

ences, the problem is largely a matter of emphasis. "We are the only industrialized country in the world that allows science to be an elective in some high schools," Miller notes.

"We don't exactly make science accessible," Malcolm adds. "Science in school is so compartmentalized, and it doesn't get related to what students might want to know or how it might relate to their everyday lives. The story line is not coherent, and we don't teach real inquiry." 
Vol. 77, No. 38, September 17, 1996

Fig. 1. Swath mapping bathymetry (in meters) from North Fiji cruise and Starmerdata. The South Pandora Ridge and the Tripartite Ridge spreading axes (mainly in red, yellow and purple) make up a roughly east-west broad arch. The axes are divided in several segments by trans-
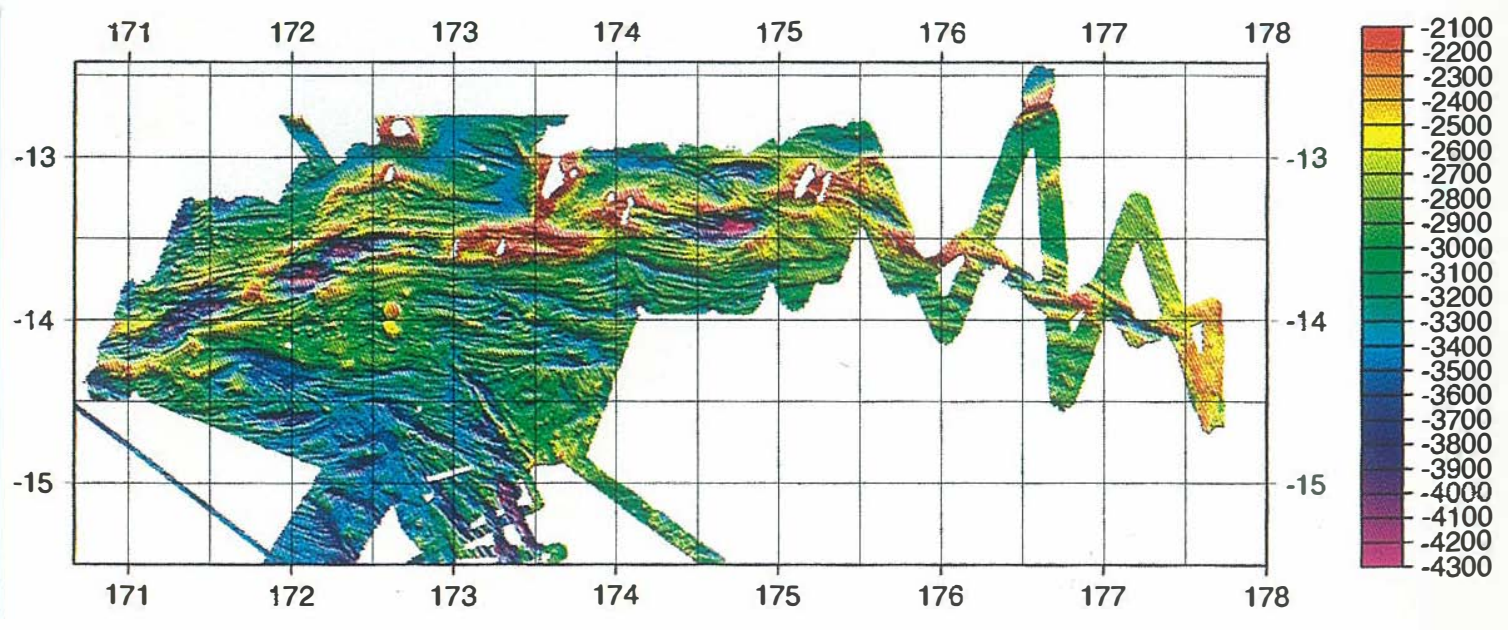

form zones. Outside, the seafloor of the Central Plateau displays a tectonic pattern linked to this spreading. In the southern area, the Central Spreading Ridge of the North Fiji Basin (mainly northwest-southeast) ends against the Central Plateau. 